\title{
Risks and Indirect Losses Due to the Utilisation of Computerized Systems \\ English Summary
}

The research undertaken for the Geneva Association, in the financial sectors (banks, insurance) and in the sectors of industry, trade and services in Western Europe, had the following principal objectives :

- to determine the nature and importance of the risks of indirect losses induced by the use of computer systems in a company ;

- to frame the policy to be pursued by the insurance industry in this field.

In order to formulate the conclusions of the study, several working groups were assembled, approximately 100 investigations were carried out and three case studies were made.

The main points which emerged from this study are sketched below.

\section{A. General reliability of computer systems}

There is an obvious need to improve the reliability of computer systems, especially in the sectors of industry and trade, as regards both systems of information and equipment and soft ware (programmes).

The insurers must, in our opinion, impose certain standards of prevention/detection of hazards, particularly as regards procedures for protection against accidents and repairs in case of breakdown.

To this end, we suggest :

- a more effective assistance to the insured and periodic controls of the safe operation of the computer systems ;

- inducements to the insured - through the premium rates - to pursue and maintain a coherent and comprehensive policy of prevention of accidents in computer systems.

B. Direct Financial Losses

Although Direct Financial Losses are not the object of this study, the following points may be noted :

- The use of computer systems entails risks of Direct Losses, especially when applied to the control of Industrial Processes, to Financial and Commercial Management and to Personnel and Production Management.

- A centralized computer system entails a higher level of risks than a decentralized (divided) system.

- A substantial share (over 33 per cent) of the risks of direct financial losses is borne by the company itself (largely because, in our opinion, these risks are not properly evaluated by the insured) ; a small part of these risks (11 per cent) appears to be adequately insured; however, we believe that at least half of the potential direct losses are covered only to the extent of approximately 60 per cent of their real value. 
- We have also observed that in this field, although this type of insurance has been in existence for over 25 years, there is a significant communication problem between insurers and insured.

C. Indirect losses

- Indirect losses have been studied under the following headings :

- Indirect Operational Losses (Consequential Losses) ;

- Civil Liability of Operation ;

- Professional or Contractual Civil Liability ;

- Liability for Products ;

- Civil Liability of the Holder of Information.

- It is clear that, even though the computer systems have not created these various types of risks (except perhaps for Professional Civil Liability) they have nevertheless substantially increased the magnitude of the risk previously existing in organizations of the manual type, and have created new risks (the breakdown of automatic equipment, for example).

From the study of a sample, it was noted that :

- approximately one company out of six has not taken any coverage even against such basic risks as : Indirect Operational Losses, Operational Civil Liability ;

- at least one company out of two has not taken any coverage against the risks inherent in Professional Civil Liability, Civil Liability for Products or Civil Liability of the Holder of Information.

- The estimate made of the overall coverage rates, defined as

Upper limits of the amounts insured

showed, especially for the management applications, a considerable under-estimation in the amounts insured, due in particular to the fact that computer systems increase the old risks and create new risks.

As a whole, assuming a comparative reliability in the results obtained with the study sample, we may estimate the potential losses at least at three times the total amount insured.

Even taking into account the fact that the self-insurance phenomenon considerably reduces the potential mentioned above, we believe it is quite realistic to estimate the potential insurable market at twice the size of the existing one.

It may be noted that :

- the companies belonging to the industrial sector have a better coverage than those belonging to the other sectors examined ;

- as a general rule, companies in the United Kingdom, the Federal Republic of Germany, Switzerland and Scandinavia show coverage rates that are distinctly higher than those of companies in the other countries considered;

- the amplitude of the level of risk is approximately twice as large for those applications of the "Processes Control" type (Maximum: SF 25 million; average SF 5 million) as for the management applications (Maximum : SF 15 million and average SF 2 million); 
- 80 per cent of the companies in the sample have already experienced one or several accidents of the type considered ;

- the study of Indirect Losses by type of incident shows the following values :
- Equipment
$47.4 \%$
- Method of Utilization
$31.4 \%$
- Utilization
$7.5 \%$
- Other
$13.7 \%$

(Fraud, Sabotage)

- the industrial sector is potentially the carrier of the highest level of risks

(in Millions of Swiss Francs)

Industry

Max.

Median

Services

25

3.5

Trade

- the level of risk is greater when the computer system is more advanced : the highest potential indirect losses are induced by the real time systems ;

- the potential indirect losses concern damages to:

- individuals

$26.8 \%$

- the company itself

$41 \%$

- customers that are Corporate Bodies

$28.1 \%$

- other

$4.1 \%$

i.e. almost 60 per cent in the field of Civil Liability;

- it should be noted that a comparison with the results of the study carried out for the "Geneva Association" in 1975 shows that :

- the present estimates are of the same level as the forecasts made by the experts for the next decade,

- the methods of utilization of computer systems, particularly the soft ware (application programmes) are now considered as involving a higher level of risk than had been the case during the 1975 study.

D. Various problems encountered in the course of the study

- In the industrial sector, particular emphasis had been placed on the increase of "Products" Risks; the participants ask for the support of the insurers in the formulation of a reasonable and economically sound policy.

- An effort should be made to rationalize the various existing legislations.

- Present methods of framing premium rates have been the subject of criticism, in particular because the insured feel that their efforts of accident prevention are not being adequately rewarded by lowered premiums.

- The insurers are asked to take fully their responsibilities in the matter of education and advice ; the part played by brokers is regarded as satisfactory. It is becoming both necessary and urgent to establish good communications between insurers and insured. 


\section{E. Recommendations}

We suggest, as we conclude this study, that the insurance industry should :

- make an additional effort to redefine its policy and products in this field, by adapting them to the changing conditions of the functioning of companies which are becoming more and more computerized;

- define an overall formalized and modular methodology of work in order to deal with the problem of Indirect Losses induced by computer systems. This methodology must take into account the various necessary stages in the work (identification of risks, evaluation of risks, possible solutions, control and checking of the safeguards introduced ...);

- organize, in the first place to help the insured and later to instruct the addressees concerned, pluridisciplinary teams capable in particular of re-examining the products involved and of defining a methodology ;

- make an intelligent effort for the promotion and marketing of Indirect Loss Insurance (the first objective would seem to be to attract the attention of the managers of the companies concerned).

The increasing dependence of our society upon computer systems requires a better assessment of the risks actually created and the introduction of a series of concrete measures in order both to prevent and to insure the risks in question.

The insurance industry can and must be the active agent in every one of the phases of reflection and action which are necessary in this connection. 